\title{
SISTEMA LÚDICO PARA AUMENTAR O TREINAMENTO DE CAMINHADA PARA CRIANÇAS COM LIMITAÇÕES NEUROPSICOMOTORAS.
}

\section{LUDIC SYSTEM FOR INCREASING GAIT TRAINING FOR CHILDREN WITH NEUROPSICOMOTORIAL LIMITATIONS.}

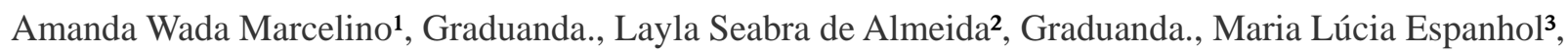
Graduanda., Luiza Helena Boueri Rebello ${ }^{4}$, D.Sc., Giuseppe Amado de Oliveira ${ }^{5}$, D.Sc.

(1) Universidade Federal Fluminense - UFF e-mail: amandawada@id.uff.br

(2) Universidade Federal Fluminense - UFF e-mail:laylaseabra@gmail.com

(3) Universidade Federal Fluminense - UFF e-mail:_luci.espanhol@gmail.com

(4) Universidade Federal Fluminense - UFF e-mail:luizarebello@id.uff.br

(5) Universidade Federal Fluminense - UFF e-mail:gamado@id.uff.br

Tecnologia assistiva, desenvolvimento neuropsicomotor, treino da marcha

O treino da marcha, em seus diversos propósitos, pretende proporcionar autonomia, e desenvolvimento de movimentos, principalmente dos membros inferiores na deambulação. O projeto desenvolvido, na área de tecnologia assistiva infantil, promove uma maior interação, entre a criança, treino e fisioterapeuta, estimulando a prática do exercício proposto, com maior segurança, sem alto custeio.

Assistive Technologies, psychomotor development, gait training

The gait training, in a several purposes, intends to provide autonomy, and development of movements, mainly of the lower limbs in the ambulation. The project developed in the area of children's assistive technology, promotes a greater interaction between the child, training and physiotherapist, stimulating the practice of the proposed exercise, with better safety, without high cost. 
$16^{\circ}$ Ergodesign - Congresso Internacional de Ergonomia e Usabilidade de Interfaces Humano Tecnológica: Produto, Informações Ambientes Construídos e Transporte

$16^{\circ}$ USIHC - Congresso Internacional de Ergonomia e Usabilidade de Interfaces Humano Computador

CINAHPA | 2017 - Congresso Internacional de Ambientes Hipermídia para Aprendizagem.

\section{Introdução}

O desenvolvimento de uma criança envolve etapas que evoluem de forma natural como tatear, engatinhar e andar, porém essas etapas podem não acontecer de forma natural. De acordo com a Cartilha do Censo de 2010, estima-se que no Brasil aproximadamente $7,5 \%$ da população compreendida entre 0 e 14 anos de idade apresentam algum tipo de deficiência, sendo que $5,3 \%$ são deficientes visuais, $5,1 \%$ auditivos, $1 \%$ com deficiência motora e $0,9 \%$ com deficiência mental ou intelectual (OLIVEIRA, 2012). A Organização Mundial da Saúde (OMS) define deficiência como uma condição de ausência ou não funcionamento adequado de parte do corpo.

As limitações, sejam elas físicas, visuais, auditivas ou mentais, são características de uma pessoa com deficiência que podem ser compensadas, aliviadas ou neutralizadas com a utilização de Tecnologia Assistiva. Em 2006 foi instituído o Comitê de Ajudas Técnicas (CAT) com o objetivo de aperfeiçoar o desenvolvimento da Tecnologia Assistiva no Brasil que teve a seguinte definição:

\section{"Tecnologia Assistiva é uma área do conhecimento, de característica interdisciplinar, que engloba produtos, recursos, metodologias, estratégias, práticas e serviços que objetivam promover a funcionalidade, relacionada à atividade e participação, de pessoas com deficiência, incapacidades ou mobilidade reduzida, visando sua autonomia, independência, qualidade de vida e inclusão social (CAT, SEDH, 2007)."}

Recursos como órteses, próteses, utensílios adaptados, ambientes adaptados e equipamentos necessários para terapia de reabilitação, que podem ser utilizados para proporcionar uma melhora na mobilidade e interação da pessoa com deficiência objetivando ao máximo a vida independente, são identificados como Tecnologia Assistiva (TA), assim como os serviços prestados por profissionais de diferentes áreas, desde fisioterapeutas a designers de produto. A criação de um novo produto em TA tem o objetivo de dar maior independência à pessoa com deficiência aumentando assim, sua qualidade de vida e inclusão social.

Os recursos utilizados em clínicas de reabilitação e fisioterapia para a melhora da condição física e motora de crianças muitas vezes são adaptados e não específicos para o público infantil. Esse fato foi observado na instituição onde ocorreu o estudo de caso mencionado neste artigo. A instituição tem como objetivo melhorar a qualidade de vida de crianças, adolescentes e adultos com deficiência. Em 2006 foi detectado por amostragem que 4,95\% da população na cidade de Niterói possui uma deficiência motora (AFR, 2006). Esses dados motivaram a realizar um estudo no setor de Fisioterapia Pediátrica, de uma Instituição de Reabilitação, para criação de um produto que auxilie o desenvolvimento neuropsicomotor.

O desenvolvimento neuropsicomotor é considerado um processo sequencial relacionado a idade cronológica da criança. Os avanços acontecem dentro de uma faixa etária como a marcha independente que pode acontecer entre 11 e 14 meses, ocorre o atraso quando o desenvolvimento para sua faixa etária na área neurológica, psíquica e motora está aquém do esperado (MACEDO, 2013). Esse atraso no desenvolvimento motor pode ser constatado em crianças com Mielomeningocele (MMC) e Síndrome de Down, que acometem os pacientes que fazem parte desse estudo de caso. Dentre os exercícios executados na instituição visitada está o treino da marcha que compreende um padrão complexo de contrações musculares em diversos segmentos do corpo, proporcionando assim o deslocamento do mesmo.

\section{"A marcha pode ser descrita como uma} progressão translacional do corpo como um todo, produzida por movimentos rotatórios de segmentos corporais coordenados. A marcha normal é rítmica e é caracterizada pela alternância entre movimentos propulsivos e retropulsivos das extremidades inferiores. " (NORKIN, 1992) apud (SOUZA, 2010) 


\section{$16^{\circ}$ \\ ERGODESIGN USIHC CINAHPA}

$16^{\circ}$ Ergodesign - Congresso Internacional de Ergonomia e Usabilidade de Interfaces Humano Tecnológica: Produto, Informações Ambientes Construídos e Transporte

$16^{\circ}$ USIHC - Congresso Internacional de Ergonomia e Usabilidade de Interfaces Humano Computador

CINAHPA | 2017 - Congresso Internacional de Ambientes Hipermídia para Aprendizagem.
O treino da marcha possui seus diversos objetivos, dentre as funções do treino, pode se citar, a deambulação, curta ou longa, o equilíbrio, o controle da postura ereta, o aumento da velocidade, a regulação da distância do passo, o controle do pé de modo a permitir que ele supere os obstáculos e garanta que o calcanhar toque o solo de modo cuidadoso (PERRY, 2004). Aos padrões funcionais do corpo humano, determinantes para a marcha são de rotação pélvica, obliquidade pélvica, flexão do joelho na fase de apoio, mecanismos do tornozelo e deslocamento lateral do corpo segundo HERBERT SIZÍNIO e XAVIER RENATO (2003) apud KOVALSKI e MEJIA (2016).

Existem teorias estudadas a respeito da marcha e da forma como realizar o tratamento, conforme o conhecimento do fisioterapeuta e a linha seguida, ele irá conduzir as atividades de recuperação, observando todas as fases, com os músculos e membros requeridos, principalmente quadril e joelho, e limitações apresentadas pelo paciente, segundo SOUZA (2010). A avaliação da marcha pelo fisioterapeuta, irá identificar qual o tipo de deambulação exercida, visto que há denominações conciliando características musculares e de posicionamento predominantes em cada condição apresentada (HALL, 2007).

Segundo HOFFER (19973) apud GARBELLINI a Classificação funcional de marcha é definida em deambuladores comunitários, domiciliares, nãofuncionais e não deambuladores. Os comunitários são pacientes que deambulam dentro e fora de casa com ou sem o auxílio de órteses e cadeira de rodas apenas para longas distâncias. Domiciliares deambulam apenas em casa com o auxílio de órteses e usa cadeira de rodas para todas as atividades externas. Os deambuladores não funcionais andam apenas durante a terapia, seja em casa, na escola ou no hospital. Os não deambuladores usam sempre a cadeira de rodas para suas locomoções. De acordo com a classificação da marcha são definidos os exercícios que a criança com deficiência irá realizar.
No caso de crianças com MMC, que é um tipo de defeito de fechamento do tubo neural, a deambulação não é possível para todas as crianças, apenas $60 \%$ das crianças possuem marcha até os 10 anos, $26 \%$ não deambulam e $15 \%$ andam com auxílio de órteses em casa (EBERT, 2011). De acordo com cada paciente, haverá um foco maior em um determinado exercício fisioterapêutico. $\mathrm{Na}$ reabilitação de crianças com MMC, que foram casos estudados mais recorrentes entre as crianças da instituição, o treino possuía uma finalidade de autonomia, de proporcionar ao paciente, a possibilidade de percorrer curtas distâncias sem a necessidade de equipamento como órteses, ou até mesmo de longas distâncias, de recuperar a marcha (KOVALSKI; MEJIA, 2016).

\section{Desenvolvimento}

O objetivo desta pesquisa é criar um produto que possa ser utilizado por crianças de 2 a 10 anos de idade que necessitem do treino da marcha para adquirir ou melhorar suas competências para deambulação. Embora os diagnósticos de deficiência sejam diferentes, o treino é o mesmo, e para melhor entender como funciona o treino da marcha com essas crianças foram feitas visitas à instituição de reabilitação, com a finalidade de observar e registrar como ocorrem a execução dos exercícios, sempre com a supervisão e orientação das fisioterapeutas responsáveis. Para definir o produto a ser criado é importante entender como funciona o sistema da marcha, em qual ambiente está inserido e qual a relação com outros sistemas existentes, segundo MORAES e MONT'ALVÃO (2012) se na fase de projetação não se tem todas as informações, há uma perda de eficiência, e pode até mesmo ocorrer a impossibilidade de realizar o projeto. É importante também conhecer os usuários e suas especificidades. Segundo PHEASANT (1997) apud MORAES e MONT'ALVÃO (2012), o design de um produto deve ter como base as características físicas e mentais do seu usuário.

\subsection{Caracterização da tarefa}




\section{$16^{\circ}$ \\ ERGODESIGN USIHC CINAHPA}

$16^{\circ}$ Ergodesign - Congresso Internacional de Ergonomia e Usabilidade de Interfaces Humano Tecnológica: Produto, Informações Ambientes Construídos e Transporte

$16^{\circ}$ USIHC - Congresso Internacional de Ergonomia e Usabilidade de Interfaces Humano Computador

CINAHPA | 2017 - Congresso Internacional de Ambientes Hipermídia para Aprendizagem.
O treino da marcha é diferenciado de acordo com cada paciente e as limitações que ele possui, sendo o objetivo do sistema a melhora da marcha sendo ela de curta ou longa distância para que o paciente tenha uma maior independência e evolução na vida cotidiana possível. A sessão tem a duração de meia hora, podendo ocorrer pequenas pausas nas quais as fisioterapeutas utilizam de brincadeiras para tornar a tarefa menos incômoda e cansativa à criança.

Em geral, as crianças que executam o treino da marcha realizam três principais exercícios:

Flexão do quadril e extensão do joelho: Nesse treino, no percurso são acrescentados obstáculos no qual obriga a criança a elevar o joelho e flexionar o quadril. O produto utilizado para realiza-lo é feito de madeira e não possui uma estrutura que possa trazer segurança a criança quando ocorrem quedas e desequilíbrio.

Exercício de equilíbrio: O paciente tem que ter estabilidade na sua postura estática e no deambular, os materiais utilizados nesse treino são improvisados, e não possuem uma eficiência adequada para o treino.

Exercício de ritmo e controle do passo: $\mathrm{O}$ paciente tem que possuir um ritmo adequado para a deambulação, enfrentando obstáculos ou não, esse treino utiliza uma variedade de produtos, como barras paralelas, obstáculos de madeira, escada e rampa, sendo o mais complexo exige da criança mais esforço e concentração.

\subsection{Análise Comportamental}

A dimensão física da carga de trabalho das fisioterapeutas é grande, pois elas têm que estar sempre atentas ao que acontece com a criança. Qualquer erro no exercício executado pelo paciente ou falta de atenção pode proporcionar uma queda, e, a fisioterapeuta tem que estar sempre alerta para que isso não ocorra. Em alguns casos também é grande o esforço da criança ao realizar o treino devido à gravidade de sua deficiência.
Quanto a dimensão cognitiva da carga de trabalho, é primordial que as fisioterapeutas tenham conhecimento prévio sobre as patologias e limitações de cada paciente e também tenham em mente o exercício que cada criança irá realizar para otimizar o tempo. Cada criança possui uma sequência e intensidade de atividades diferentes e os fisioterapeutas tem que estar atentos ao que pode ser feito, quais os exercícios fundamentais e as consequências de cada movimento.

O ambiente onde é realizado o treino da marcha é também o mesmo onde pacientes de 30 dias a 12 anos fazem fisioterapia. Frequentemente há bebês que choram e isso chama a atenção de outras crianças com mais idade, as vezes param de realizar o treino para observar. Pode ocorrer também de a criança chegar cansada ao treino, pois, dependendo do diagnóstico ela também pode ter seção de fonoaudiologia, psicologia e terapia ocupacional em ambientes diferentes. É perceptível a falta de interesse de a criança realizar o treino com materiais não atrativos e que geralmente não fazem parte do universo infantil.

\subsection{Reconhecimento do problema}

Através de um levantamento de dados de similares, foi observado a falta de produtos existentes que trabalhem especificamente com o treino da marcha. Muitos produtos utilizados são voltados para treinos de esportes comuns e ginásticas. Quando o produto é especifico para fisioterapia, ele costuma ter um preço elevado, no qual, prejudica ONGs e associações filantrópicas de obtê-lo, além disso, a ala infantil acaba sendo mais prejudicada do que a adulta, pois, as crianças necessitam mais de estímulos visuais e criativos para que realizem o treino com qualidade e eficiência. Segundo PIAGET (1971) apud SANTOS (2009), o desenvolvimento da criança acontece através do lúdico, ela precisa brincar para crescer. Sendo assim, pode-se tratar a brincadeira, o lúdico, como um motivador para as crianças realizarem determinadas atividades. Há um maior interesse delas, para que a tarefa seja cumprida, pois é prazeroso o seu transcorrer, não há sacrifício 
$16^{\circ}$ Ergodesign - Congresso Internacional de Ergonomia e Usabilidade de Interfaces Humano Tecnológica: Produto, Informações Ambientes Construídos e Transporte

$16^{\circ}$ USIHC - Congresso Internacional de Ergonomia e Usabilidade de Interfaces Humano Computador

CINAHPA | 2017 - Congresso Internacional de Ambientes Hipermídia para Aprendizagem.

e o esforço é amenizado pela imaginação em que são dadas as circunstâncias da brincadeira.

Nos acessórios definidos para o treino da marcha, em geral, não há estímulos com cores, formas, sons ou texturas assim como há nos brinquedos convencionais, e é comum que as crianças, ignorem o treino para prestar atenção em outros objetos ou pessoas. Não há nenhum encorajamento criativo para que a criança realize o percurso de um modo atrativo, tornando-o monótono e tedioso, prejudicando significativamente sua recuperação.

Quando a criança não está focada a realizar a tarefa, riscos e complicações podem ocorrer no treino, a repetição dos exercícios juntos com a falta de vontade faz com que a criança queira realizar o treino mais rápido do que o recomendado, podendo suceder diversos problemas, como uma possível queda, o desequilíbrio e as excessivas pausas no exercício. Além do treino se tornar pouco produtivo, o profissional que acompanha os pacientes tem sua saúde física e emocional afetada, uma criança desencorajada exige o dobro de atenção e cuidado, a fisioterapeuta tem que estar constantemente ao lado da criança, estimulando, chamando atenção e na maioria das vezes tomando posturas físicas prejudiciais para sua saúde com o passar do tempo.

\subsection{Problematização}

Após análises e observações foram identificadas algumas situações prejudiciais no treino, tanto para a criança como para o profissional. São elas:

1. A fisioterapeuta tem que ficar se curvando periodicamente par auxiliar e estimular a criança que não quer ou tem dificuldade em realizar o exercício;

2. Os pacientes não realizam o exercício corretamente, pois o aparelho utilizado não é largo o suficiente fazendo com que a criança passe a perna pela lateral do produto e não por cima;

3. Os produtos utilizados são na maioria de materiais muito duros, como madeira, quando a criança pisa em local não apropriado ou desequilibra, ela pode cair ou se machucar;

4. Produtos que não possuem um sistema de aderência podem escorregar e causar algum acidente ou ficarem se descolando do local, fazendo com que a profissional tenha que parar o exercício para recolocar no lugar, atrasando assim o treino;

5. Muitos produtos utilizados na sala de fisioterapia são improvisados e por esse motivo não são devidamente adequados para o treino, produtos pequenos ou grandes demais podem prejudicar o exercício, exigindo o dobro de atenção da criança e da fisioterapeuta;

6. Por ser um processo repetitivo e monótono os pacientes tendem a querer realizar mais rápido do que o proposto, pulando partes do exercício ou querendo não fazer mais e a fisioterapeuta tem que ficar constantemente incentivando e voltando o exercício.

\subsection{Requisitos do projeto}

Através da delimitação do problema foram classificados alguns parâmetros que o produto deve ter para um máximo desempenho e aproveitamento durante o uso. São eles: Lúdico, baixo custo de produção, facilidade de armazenamento e montagem, resistência, o amortecimento de impacto e variação de treino oferecido.

Lúdico: Por ser tratar do setor da fisioterapia infantil, o produto a ser desenvolvido, deverá ser visivelmente atrativo para as crianças, motivar a imaginação e a brincadeira durante o treino, para que o exercício não seja monótono e que a criança se sinta bem em realiza-lo.

Baixo custo de produção: muitos dos materiais utilizados na Instituição são adaptados devido à falta de variedades em produtos específicos e também ao alto custo. $\mathrm{O}$ baixo custo dos materiais e a facilidade em que são encontrados tornaria possível até mesmo a oficina da instituição reproduzir. 


\section{$16^{\circ}$ \\ ERGODESIGN USIHC CINAHPA}

$16^{\circ}$ Ergodesign - Congresso Internacional de Ergonomia e Usabilidade de Interfaces Humano Tecnológica: Produto, Informações Ambientes Construídos e Transporte

$16^{\circ}$ USIHC - Congresso Internacional de Ergonomia e Usabilidade de Interfaces Humano Computador

CINAHPA | 2017 - Congresso Internacional de Ambientes Hipermídia para Aprendizagem.
Fácil armazenagem e montagem do produto: sendo que o treino dura 30 minutos o produto precisa estar sempre pronto para ser utilizado, o produto tem que ser prático de ser utilizado para melhor aproveitamento do tempo de treino.

Resistência, amortecimento de impacto e segurança: Os pacientes trazem fatores e gravidades de diversos níveis, as crianças possuem uma necessidade e atenção maior que os adolescentes e adultos, o produto tem que ter um sistema de proteção para quedas e a acidentes, ser higienizado facilmente e ser resistente aos grandes níveis de impacto que o produto vai absorver.

Variação de treino: O treino da marcha costuma ser rápido, porém, é preciso realizar alguns exercícios específicos, a troca constante de aparelho leva a perda de tempo e de estimulo na criança. $\mathrm{O}$ objetivo é desenvolver um produto que proporcione mais exercícios em um aparelho prático, seguro e atrativo para as crianças que necessitam realizar o treino da marcha.

\subsection{Desenvolvimento do protótipo}

O produto desenvolvido tem como objetivo qualificar e estimular o treino da marcha em crianças de 0 a 12 anos que necessitam de exercícios. Para a escolha do material trabalhado foi considerado principalmente a segurança do paciente e a resistência da matéria prima. Crianças, principalmente com atraso no desenvolvimento neuropsicomotor, estão sempre sujeitas a quedas e desequilíbrio, para evitar acidentes as características mecânicas dos materiais foram pesquisadas. A escolha do material teve a finalidade de proporcionar maior segurança ao usuário, assim a principal característica foi a de amortecer impactos e não ser tóxicos. Os materiais que a criança terá contato são: 1. o tatame de EVA (Etil Vinil Acetato) de 10mm de espessura que tem como características mecânicas de ser leve, resiliente, durável, atóxico, inodoro, lavável, flexível e aderente de acordo com as especificações fornecidas pelo fabricante (EUREKA, 2015). 2. o tubo de polietileno expandido, popularmente conhecido como espaguete flutuante, usado para os obstáculos é leve, inodoro, maleável, lavável, de fácil manuseio e não possui quaisquer contraindicações.

O tatame pode ser utilizado em ambas às superfícies, cada um em um treino diferente, o primeiro (figura 1) foi analisado onde ficariam as estampas e obstáculos de acordo com o passo da criança. Para confirmar o tamanho aproximado de um passo, foram realizadas simulações do passo das crianças, tendo em média 30 centímetros, desse lado do produto, podem ser treinados dois exercícios diferentes, com obstáculos ou marcha livre com equilíbrio.

Para crianças maiores os obstáculos podem ser encaixados de um modo que o nível de flexão do quadril e de extensão do joelho que o paciente realiza será adequado à sua altura e ao grau de dificuldade do exercício. No verso do produto existe outra estampa com o mesmo tema (figura 2), porém, os exercícios focados nesse é para marcha livre sem obstáculos e para crianças que possuem um grau de dificuldade maior, no qual, não conseguem realizar o movimento de flexão do quadril e joelhos e, que necessitam treinar a marcha para pequenas distancias com ritmo. As dimensões do tapete são proporcionais ao espaço disponível entre as barras fixas já existentes onde são realizados treinos, tendo como medida final $50 \mathrm{~cm}$ de largura por $160 \mathrm{~cm}$ de comprimento.

O tapete possui uma estampa com tema de fundo do mar, para que as crianças se interessem e interajam no decorrer do treino, as cores e o tema foi sugerido pelas próprias crianças que fazem o treino. Segundo HELLER (2013), a cor azul é a cor predileta entre homens e mulheres, é a cor da simpatia e da harmonia e, apesar de fria, o azul é uma cor calmante e positiva. Para tornar o tatame mais atrativo os peixes e os obstáculos são estampados em cores quentes e claras que contrasta com o fundo escuro. Os desenhos possuem traços arredondados para que remetesse a um desenho infantil. 


\section{$16^{\circ}$ \\ ERGODESIGN USIHC CINAHPA}

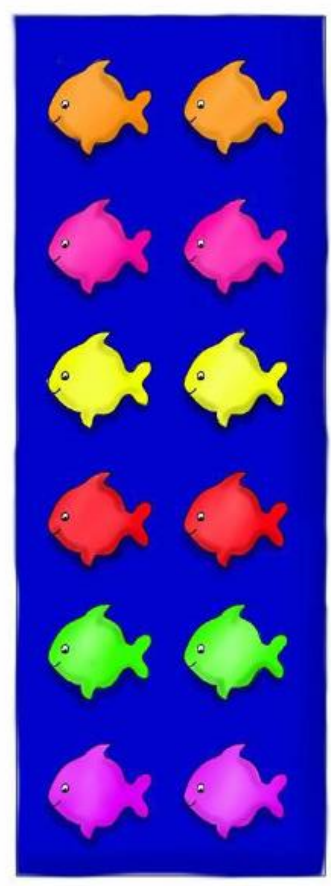

Figura 1 - Simulação da estampa do tapete frente.

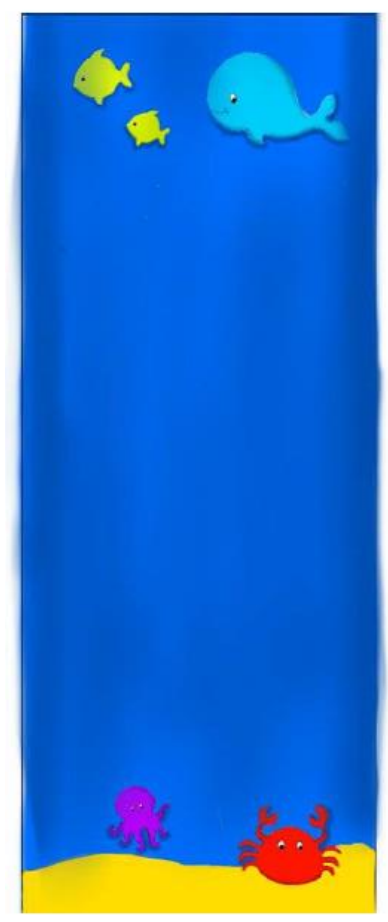

Figura 2 - Simulação da estampa do tapete verso. $16^{\circ}$ Ergodesign - Congresso Internacional de Ergonomia e Usabilidade de Interfaces Humano Tecnológica: Produto, Informações Ambientes Construídos e Transporte

$16^{\circ}$ USIHC - Congresso Internacional de Ergonomia e Usabilidade de Interfaces Humano Computador

CINAHPA | 2017 - Congresso Internacional de Ambientes Hipermídia para Aprendizagem.

\section{Validação do Protótipo}

A avaliação do produto final foi realizada em duas visitas à instituição de reabilitação para que outros pacientes que não foram observados e não fizeram parte do estudo pudessem também experimentar o treino da marcha no "Tapete Fundo do Mar". O uso do produto foi bem aceito tanto pelos profissionais como pelos pacientes, de acordo com o feedback das fisioterapeutas o desempenho e rendimento das crianças melhoraram. O produto atende uma gama de crianças de várias idades e dificuldades diferentes, por ter os obstáculos móveis a fisioterapeuta consegue ter mais opção de treino, dificultando cada vez mais o exercício e exigindo da criança mais concentração.

A figura 3 apresenta um dos pacientes do setor de fisioterapia infantil, não presente no estudo de caso, mas que testou o produto. $\mathrm{O}$ paciente que tem 11 anos de idade tem encurtamento do Tendão de Aquiles e tem como objetivo caminhar apoiando o calcanhar no chão. Realizou o treino "passando obstáculos de lado" no qual são colocados todos os obstáculos no tatame e a criança tem que passar de lado, forçando o calcanhar a encostar contra o tapete para ter equilíbrio. Segundo a fisioterapeuta que o acompanha, considerou o nível do exercício difícil, mas eficaz, pois colocar toda a planta do pé no chão é o objetivo do treinamento para esse paciente. $\mathrm{O}$ treino da figura 4 possui os obstáculos com uma altura mais elevada onde o tubo de polietileno é sobreposto um ao outro. O objetivo é que o paciente faça todos os movimentos do passo pisando nos desenhos de peixe, encostando todo o calcanhar na superfície do tatame, o que foi um treino muito bem avaliado pela fisioterapeuta que o acompanha

O treino para a paciente, que tem 2 anos de idade, diagnosticada com mielomeningocele, foi bem lúdico como podemos ver na figura 5 , pois a 


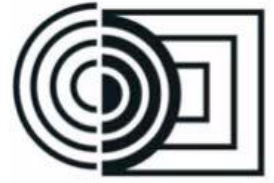

\section{$16^{\circ}$}

ERGODESIGN USIHC CINAHPA

$16^{\circ}$ Ergodesign - Congresso Internacional de Ergonomia e Usabilidade de Interfaces Humano Tecnológica: Produto, Informações Ambientes Construídos e Transporte

$16^{\circ}$ USIHC - Congresso Internacional de Ergonomia e Usabilidade de Interfaces Humano Computador

CINAHPA | 2017 - Congresso Internacional de Ambientes Hipermídia para Aprendizagem.

fisioterapeuta orientou a criança a alimentar os peixes, dando estrelinhas. Ela fez o percurso, muitas vezes, primeiramente colocando a estrelinha sobre o peixe uma a uma, e depois retirando a estrelinha, dando um passo a cada obstáculo, levantando a perna sem rotacionar muito o quadril. Em nenhum momento foi necessário que a fisioterapeuta intervisse no treino, somente sua orientação verbal foi necessária para a execução de todos os exercícios. O objetivo é de que a paciente tenha uma deambulação normal.

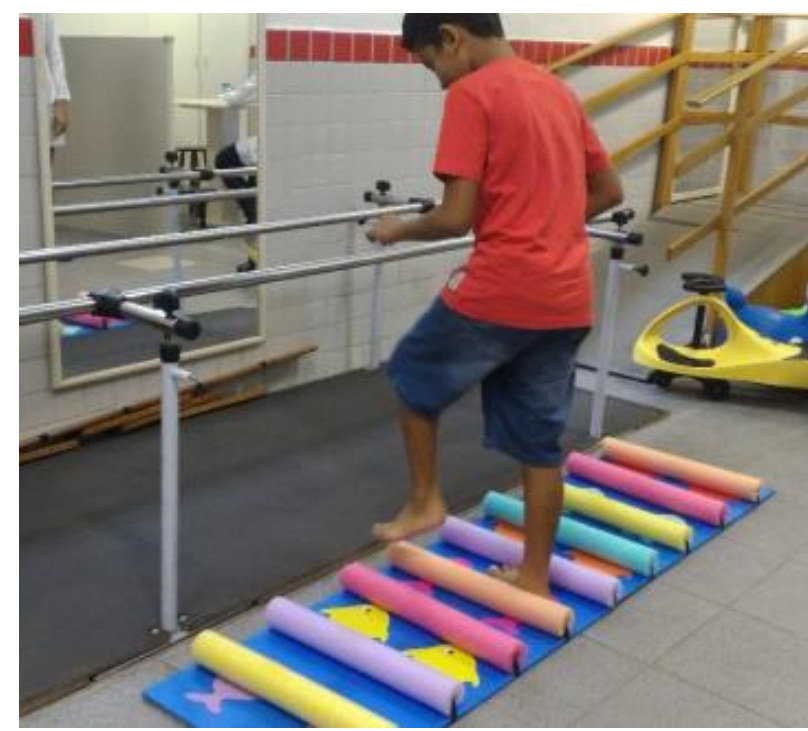

Figura 3 - Uso e validação do tapete, treino 1

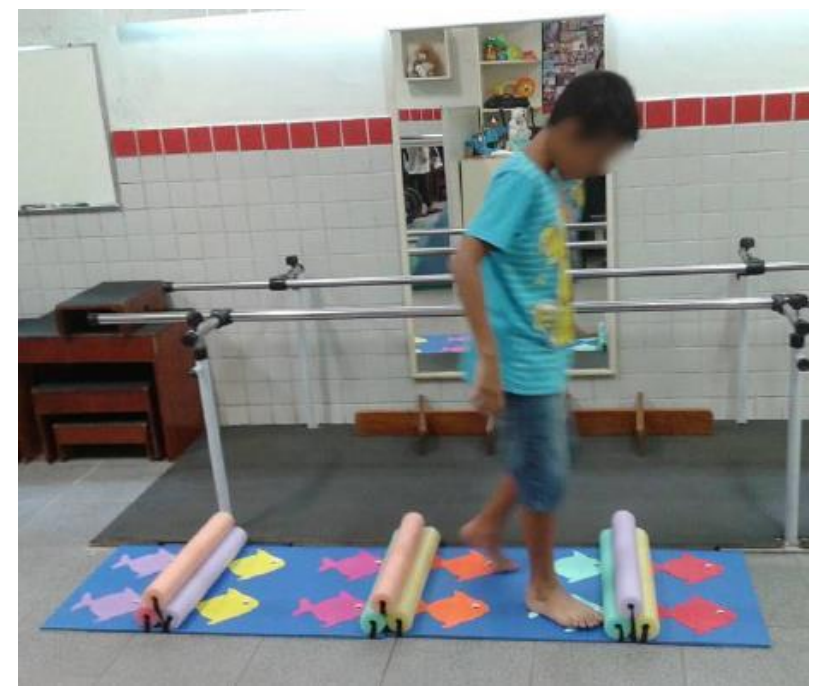

A terceira paciente, também com mielomeningocele, fez o treino sem obstáculos, figura 6 , devido ao fato de que em seu caso, não há flexão do joelho. Contanto, a parte lisa possui desenhos, que estimulam e a paciente ficou empolgada, principalmente para chegar nas partes que possuíam peixes (começo e fim). Segundo a fisioterapeuta para percorrer esse percurso Isadora tem que fazer um grande esforço devido à gravidade de sua lesão, com o auxílio de órteses seu objetivo no treino da marcha é a deambulação domiciliar.

\section{Conclusão}




\section{$16^{\circ}$ \\ ERGODESIGN USIHC CINAHPA}

$16^{\circ}$ Ergodesign - Congresso Internacional de Ergonomia e Usabilidade de Interfaces Humano Tecnológica: Produto, Informações Ambientes Construídos e Transporte

$16^{\circ}$ USIHC - Congresso Internacional de Ergonomia e Usabilidade de Interfaces Humano Computador

CINAHPA | 2017 - Congresso Internacional de Ambientes Hipermídia para Aprendizagem.
Com os testes e todo o estudo realizado para o desenvolvimento do projeto, foi observado ao final que as crianças se sentem mais à vontade para realizar o exercício e interagem mais com o treino, com o lúdico, elas possuem um estímulo maior, fazendo-o então com mais qualidade e com maior atenção. A profissional responsável que antes disputava com as adversidades, barulhos e distrações do ambiente, mais atrativas para criança que o exercício, no teste final, não necessitou mais ficar chamando a atenção da criança e acaba por estimular o treino com brincadeira e jogos. Outro ponto do requisito que foi o de baixo custo, diversificou o ambiente de uso do produto que, além de servir para as associações, o produto pode ser introduzido no ambiente familiar, no qual, as crianças possam reforçar o treino fora da sala de recuperação. Com o produto, o treino que antes, observados às reações das crianças, era visto como um exaustivo tempo de exercício, depois de introduzido o produto, foi claramente bem recebido pelos pacientes e fisioterapeutas, mudando o ambiente, acrescentando uma característica infantil, necessária ao estímulo do espaço.

No caso específico da paciente que aparece na figura 5 acima, foi perceptível a mudança de comportamento diante da novidade. $\mathrm{O}$ grupo pode acompanhar seu treino durante dois meses nos antigos equipamentos, que eram sem cores, de madeira e não específicos para crianças, e o comportamento da paciente era apático. A fisioterapeuta precisava motivá-la o tempo todo e estar atenta a uma possível queda, pois os materiais não absorviam impacto, o que significava um risco. Com o novo "Tapete Fundo do Mar" a paciente estava brincando com sua série de exercícios, nada em volta lhe tirava a atenção, seu foco eram apenas os obstáculos do tapete. Naquele momento o exercício tornou-se uma brincadeira regrada.

Segundo as fisioterapeutas a criança desenvolve-se por querer, aprende a engatinhar por querer alcançar os objetos, aprende a andar para chegar mais rápido aos lugares. Ter um sistema de treino da marcha que favoreça o lúdico, que se transforme numa uma brincadeira, faz com que ela queira praticar, queira brincar, e esse fato pode contribuir positivamente para o tratamento em geral, especialmente no que tange ao aspecto psicomotor e psicossocial.

\section{Referências}

AFR, Associação Fluminense de Reabilitação. Estudo sobre prevalência de incapacidades na cidade de Niterói, 2006. Disponível em: http://www.afr.org.br/img/poll/report/Relatorio_Ni teroi.pdf. Acesso em: 20 fev. 2017.

\section{BRASIL. Subsecretaria Nacional de Promoção dos Direitos da Pessoa com Deficiência. Comitê de Ajudas Técnicas. Tecnologia Assistiva - Brasília: CORDE, 2009. 138 p.}

\section{OLIVEIRA, L. M. B. Cartilha do Censo 2010 -}

Pessoas com deficiência. Brasília 2012.

Disponível em:

http://www.pessoacomdeficiencia.gov.br/app/sites/ default/files/publicacoes/cartilha-censo-2010pessoas-com-deficienciareduzido.pdf. Acesso em: 18 de fev. 2017.

\section{EBERT, G. Mielomeningocele - aspectos} neurológicos de uma doença multidisciplinar. In: SPERS, V. R. E.; PENACHIM, E. A. S.; GARBELLINI, D. (Orgs) Mielomeningocele: o dia a dia, a visão dos especialistas e o que esperar do futuro. Piracicaba: Unigráfica, 2011. 237p.

EUREKA. E.V.A. Vantagens e uso. Disponível em: http://www.eurekaeva.com.br/artigos/e-v-avantagens-e-uso/. Acesso em: 18 mar. 2016.

GARBELLINI, D. A fisioterapia neurológica. In: SPERS, V. R. E.; PENACHIM, E. A. S.; GARBELLINI, D. (Orgs) Mielomeningocele: o dia a dia, a visão dos especialistas e o que esperar do futuro. Piracicaba: Unigráfica, 2011. 237p. 


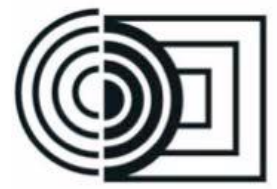

\section{$16^{\circ}$}

ERGODESIGN USIHC CINAHPA $16^{\circ}$ Ergodesign - Congresso Internacional de Ergonomia e Usabilidade de Interfaces Humano Tecnológica: Produto, Informações Ambientes Construídos e Transporte

$16^{\circ}$ USIHC - Congresso Internacional de Ergonomia e Usabilidade de Interfaces Humano Computador

CINAHPA | 2017 - Congresso Internacional de Ambientes Hipermídia para Aprendizagem.

HALL, C.M; BRODY, L.M. Exercício

terapêutico, na busca da função. 2 ed. Rio de

Janeiro: Guanabara Koogan, 2007. 844p.

HELLER, E. A psicologia das Cores: como as cores afetam a emoção e a razão. 1 ed. [tradução Maria Lúcia Lopes da Silva]. São Paulo: Gustavo

Gili, 2013. 311p.

KOVALSKI, L.R.F.N; MEJIA, D.P.M. Treino de Marcha em criança portadora de

Mielomeningocele. Goiânia, 2015. 14p.

Dissertação de Pós- Graduação - Faculdade Ávila.

MACEDO, R. Atraso no desenvolvimento neuropsicomotor, 2013. Disponível em: http://rejanemacedo.com.br/blog/atraso-nodesenvolvimento-neuropsicomotor/. Acesso em: 20 fev. 2017.

MORAES, A.; MONT'ALVÃO, C. Ergonomia: conceitos e aplicações. 4.ed. Rio de Janeiro: $2 \mathrm{AB}$, 2009. 224p.

PERRY, J. Análise de marcha sistema de Análise da marcha. 4 ed. São Paulo: Manoele, 2004. v.3, 167p.

SANTOS, C.P. A importância do lúdico na educação infantil com crianças de 5 anos. São Paulo: Faculdade Unisalesiano, 2009. 13p.

SOUZA, A.S.P. Controlo Postural e marcha humana: análise multifactorial. Portugal : [s.n], 2010.99p. 